\title{
Educação em tempo integral e programa mais educação: soluções locais para questões gerais?
}

\author{
Full-time education and more education program: \\ local solutions for general issues? \\ Enseignement à temps plein et plus education program: \\ solutions locales pour des questions générales?
}

Lígia Martha Coimbra da Costa Coelho ${ }^{1}$ Universidade Federal do Rio de Janeiro

Raphael Mota Guilarducci ${ }^{2}$ Universidade Federal do Rio de Janeiro

Saraa César Mól ${ }^{3}$

Universidade Federal do Rio de Janeiro

\begin{abstract}
Resumo: Este ensaio problematiza 'soluções locais' implantadas por dois municípios mineiros, a partir da indução pelo programa federal 'Mais Educação' (PME), implementado entre 2008 e 2014. Realizamos uma pesquisa bibliográfica a partir dos conceitos educação em tempo integral e indução, e pesquisa documental ancorada em dispositivos normativos federais e municipais. A primeira seção evidencia o conceito de educação em tempo integral subjacente ao PME e em sua política indutora, enquanto a segunda apresenta os desenhos de cada experiência, a partir da indução do Programa. Nas Considerações, apresentamos limites e possibilidades da indução da educação integral em tempo integral na contemporaneidade.
\end{abstract}

Palavras-chave: Políticas de educação em tempo integral. Indução. Educação integral.

Abstract: This essay problematizes 'local solutions' implemented by two cities of the state of Minas Gerais, based on the induction performed by the federal program 'More Education' (PME), implemented between the years of 2008 and 2014.. We conducted a bibliographical research, based on the concepts of full-time education and induction, and a documental research anchored in federal and municipal normative documents. The first section demonstrates the concept of full-time education, which integrates the PME in its inductor model, while the second section presents the designs of each experience, from the induction realized in the municipal context. In the conclusion section, we present limits and possibilities of the induction of full-time integral education in contemporary times.

Keywords: Full-time education policies. Induction. Integral Education.

\footnotetext{
${ }^{1}$ Doutora em Educação pela Universidade Federal do Rio de Janeiro (UFRJ); Docente do Programa de PósGraduação em Educação da Universidade Federal do Estado do Rio de Janeiro (UNIRIO); Coordenadora do Núcleo de Estudos: Tempos, Espaços e Educação Integral (NEEPHI/UNIRIO). E-mail: ligiamartha25@outlook.com. ORCID: https://orcid.org/O000-0002-3892-3308. Lattes: http://lattes.cnpq.br/4550861408643613

${ }^{2}$ Doutorando em Educação pela Universidade Federal do Rio de Janeiro (UFRJ) e Mestre em Educação pela Universidade Federal do Estado do Rio de Janeiro (UNIRIO); Membro do Núcleo de Estudos: Tempos, Espaços e Educação Integral (NEEPHI/UNIRIO). E-mail: rhmguila@gmail.com. ORCID: https://orcid.org/0000-0002-8344-1 105. Lattes: http://lattes.cnpq.br/1653022698095581.

${ }^{3}$ Doutoranda em Educação pela Universidade Federal do Estado do Rio de Janeiro (UNIRIO) e Mestra em Educação pela Universidade Federal de São João del-Rei (UFSJ); Membro do Núcleo de Estudos: Tempos, Espaços e Educação Integral (NEEPHI/UNIRIO). E-mail: saraa_mol@ymail.com. ORCID: https://orcid.org/O000-0001-8413-3625. Lattes: http://lattes.cnpq.br/4441054152438687.
} 
Résumé: Cet essai problématique les "solutions locales" mises en œuvre par deux municipalités du Minas Gerais, basées sur l'induction du programme fédéral "Plus d'éducation" mis en œuvre entre 2008 et 2014. Nous avons effectué une recherche bibliographique basée sur les concepts d'éducation à temps plein et d'induction, et recherche documentaire ancrée dans les dispositifs normatifs fédéraux et municipaux. La première partie présente le concept d'éducation à temps plein qui sous-tend la PME et sa politique d'induction, tandis que la seconde présente les conceptions de chaque expérience, à partir du début du programme. Dans les Considérations, nous présentons les limites et les possibilités de l'induction de l'éducation intégrale à temps plein à l'époque contemporaine.

Mots-clés: Politiques d'éducation à temps plein. Induction. Éducation intégrale.

Recebido em: 15 de maio de 2019 Aceito em: 03 de janeiro 2020

\section{INTRODUÇÃO}

Vivemos momentos conturbados. Questões que afetam a vida em sociedade, como as identitárias, por exemplo, vêm tomando um vulto que assusta os mais desavisados. Em momentos de incerteza como este, aspectos relacionados ao campo da Educação são evocados como 'causa desse estado de coisas', ou ainda como possibilidade de minimização dos mesmos. Em quaisquer dessas situações, imputa-se quase sempre à Educação 'escolar' a função de 'tábua de salvação'. E quando essa educação acontece em meio à ampliação de jornada, as cobranças a essa instituição tornam-se tão significativas quanto seu alargamento temporal.

É nessa perspectiva que se inscreve este ensaio, apresentando projetos de educação em tempo integral desenvolvidos em âmbito municipal e levando em consideração sua indução por meio de um programa federal implementado entre os anos de 2008-2014 - o 'Mais Educação'. Com esse foco, objetivamos descrever e problematizar 'soluções locais', elaboradas e implementadas a partir dessa indução. Teriam esses projetos avançado em aspectos que os aproximam de uma concepção emancipatória de formação?

Especificamente, o foco do ensaio situa-se em propostas de ampliação da jornada escolar para o tempo integral implantadas por dois municípios mineiros - Ponte Nova e São João delRei. Ambos partiram da indução criada pelo Programa Mais Educação (PME) e construíram 'singularidades' em suas trajetórias educacionais, levando em consideração essa ampliação.

Metodologicamente, o estudo baseia-se em pesquisa bibliográfica e documental. A pesquisa bibliográfica veio ao encontro da precisão de conceitos como os de educação em tempo integral e indução. Já a investigação documental fundamenta aspectos normativos e de 
compreensão dos projetos implementados pelas duas cidades que são apresentados ao longo do texto. Contamos ainda com questões trazidas por meio de pesquisa de campo realizada nas secretarias municipais de Ponte Nova e São João del-Rei e que auxiliam, igualmente, a materializar aspectos destacados nos dois projetos.

A estrutura do trabalho divide-se em duas seções. A primeira evidencia o conceito de educação em tempo integral, focando-o no Programa Mais Educação (PME), política pública indutora que foi implantada no Brasil contemporâneo. Já a segunda parte descreve as duas experiências citadas anteriormente e apresenta situações e questões que foram problematizadas, a partir da indução do PME, possibilitando desenhos diferenciados em ambas as propostas. Nas Considerações, retomamos a questão problema que nos fizemos para este ensaio, já evidenciada em parágrafo anterior, e que traz a possibilidade emancipadora que uma educação escolar, em jornada ampliada, carrega como 'utopia provável'.

Iniciando nossa conversa neste estudo, nos perguntamos: $\mathrm{O}$ que a política de educação em tempo integral denominada de 'Mais Educação' evidencia a respeito desse tempo ampliado? E como essa política se apresenta, enquanto possibilidade de articulação com os entes federados?

\section{Programa mais educação: uma política pública indutora da educação em tempo integral?}

A discussão e implementação de projetos de ampliação da jornada escolar não se constitui mais como novidade na Educação brasileira: Desde a década de 1930, educadores como Anísio Teixeira vêm defendendo o tempo integral nas atividades escolares pressupondo, com essa ampliação, a possibilidade de construção de uma escola mais democrática (TEIXEIRA, 1957).

Embora a discussão não seja nova, é verdade que, a partir da redemocratização do país e, mais precisamente, da década de 1990, algumas propostas foram implantadas em estados e municípios brasileiros. Uma das mais significativas foi a que se instituiu no estado do Rio de Janeiro - o Programa Especial de Educação (PEE), que ampliou a jornada escolar no hoje denominado Ensino Fundamental por meio da construção de 506 escolas em tempo integral os Centros Integrados de Educação Pública - CIEPs (COELHO E CAVALIERE, 2003).

Para fins de análise neste estudo, encaminhamos nossas reflexões para a primeira década do século XXI quando, a partir de ações propostas pelo Plano de Desenvolvimento da Educação (PDE), no governo Lula, uma delas - o Programa Mais Educação (PME) - se propunha a "fomentar a educação integral de crianças, adolescentes e jovens, por meio do apoio a atividades sócio-educativas no contraturno escolar" (BRASIL, 2007b). A partir de 
dois documentos legais - a Portaria Interministerial 17, de abril de 2007 e o Decreto 7083, de janeiro de 2010 - o Programa Mais Educação foi instituído com essa finalidade. Ao reforçar, nas duas peças normativas, seu 'apoio' a atividades no contraturno escolar, o PME evidencia seu propósito de ampliar a jornada escolar para o tempo integral.

Implementado na Secretaria de Educação Continuada, Alfabetização, Diversidade e Inclusão (SECADI), o PME era financiado pelo Fundo Nacional de Desenvolvimento da Educação (FNDE), por meio do Programa Dinheiro Direto na Escola (PDDE) e do Programa Nacional de Alimentação Escolar (PNAE). Tratou-se de iniciativa que previa educação em tempo integral entendida, quando de sua regulamentação, como a “jornada escolar com duração igual ou superior a sete horas diárias, durante todo o período letivo, compreendendo o tempo total em que o aluno permanece na escola ou em atividades escolares em outros espaços educacionais" (BRASIL, 2010).

Ancorada numa perspectiva de educação integral, tal iniciativa previa implementação intersetorial - sob a responsabilidade de diferentes áreas da gestão pública, e por meio da integração com equipamentos públicos, parcerias com órgãos e outras instituições locais (BRASIL, 2010), considerando a potencialidade educadora do território. Postulava ainda a indução de uma educação intercultural, a partir de currículo perpassado pela realidade da comunidade local; do entrelaçamento entre diferentes culturas, saberes, identidades, valorizando a diversidade e relacionando os "saberes comunitários" aos "saberes escolares" (BRASIL, 2009c). Tal lógica foi apresentada como justificativa para a responsabilização de agentes educativos monitores, educadores populares, estudantes em processo de formação docente, estudantes de EJA e do Ensino Médio, além de agentes culturais tidos como referências em suas comunidades , em suas atividades, na forma de trabalho voluntário (BRASIL, 2009b).

Materializada em escolas e alunos com menor desempenho educacional e maior vulnerabilidade social (BRASIL, 2014b; 2016), a proposta do PME apresentou-se com cunho focal. Por meio da escola, mas não apenas nela, pretendia induzir a formação integral de crianças, adolescentes e jovens; a garantia da proteção e assistência social (BRASIL, 2007b); a melhoria da aprendizagem; a promoção do diálogo entre os conteúdos escolares e os saberes locais; o enfrentamento da violência, a integração entre escola e comunidade (BRASIL, 2010).

Tendo em vista esses objetivos, as atividades socioeducativas propostas pelo PME foram organizadas em "macrocampos" que, considerando as peculiaridades do território, possuíam orientações para as escolas do campo e urbanas. Para as urbanas - caso das duas experiências analisadas no artigo-, as atividades a serem oferecidas inseriam-se no macrocampo de Acompanhamento Pedagógico e em outros, a serem escolhidos pelas unidades (BRASIL, 2014b). 
Em termos gerais, é possível perceber, com Libâneo (2016), a proposta de educação integral em tempo integral do PME como estratégia para solução de problemas sociais e econômicos que afetam a ordem social e política; a menção de que o Estado divida com a sociedade e com as comunidades, as responsabilidades pela escola pública; a associação do uso da escola para controle político e social, secundarizando o processo de ensino aprendizagem e as questões de conteúdo e método promovendo, assim, o desfiguramento do espaço escolar.

Antes de caminharmos para a descrição e análises que compõem o objetivo deste ensaio - direcionando-se à identificação das similitudes e diferenciações entre o campo documental da política federal do PME e a materialização dessa política em âmbito municipal -, fazemos ainda uma breve exposição do que o Governo Federal entende com a utilização do termo indução nessa política de educação em tempo integral. Embora o programa federal Mais Educação - assim como o programa que o sucedeu, denominado Programa Novo Mais Educação (PNME) - tenha sido intitulado pelo governo de 'indutor' da jornada de tempo integral, apenas o primeiro programa se ateve a discutir, em seus documentos e em parâmetros conceituais e práticos, o que se concebe como "ação indutora".

No discurso oficial do PME, a indução se insere no contexto de reabertura democrática, mais especificamente com o advento da década de 1990, quando as políticas públicas foram constituídas de maneira a buscar respaldo na Constituição Federal (1988) recém promulgada. Em virtude do desenho constitucional e do pacto federativo, que conferem autonomia relativa aos entes federados, é que se pretendeu explorar a ideia de indução da educação em tempo integral, imputando à União um papel de incentivadora dessas propostas, mas sem assumir uma responsabilidade pela manutenção de ações que, pelo escopo dos referidos programas, deveria ser assumida pelos demais entes federados.

Nesse sentido, sob a ótica da indução, os documentos oficiais do PME indicam a necessidade de avançar na execução de uma política de educação em tempo integral descentralizada, visto que, a partir da Constituição de 1988 " a descentralização passou a ser uma diretriz importante na gestão das políticas sociais, especialmente nos aspectos de execução e coordenação (...), induzindo políticas sociais e (...) aproximando-se das demandas locais”. (BRASIL, 2009d, p. 26).

Conforme encontramos nos documentos, o papel indutor do Estado na política de educação em tempo integral se relaciona com a "disseminação das novas concepções de currículo, conhecimento e desenvolvimento humano” (BRASIL, 2009d, p. 42), oferecendo “condições técnico-financeiras”, mas ressaltando que a ação indutora do Governo Federal, no entanto, é coadjuvante, pois a oferta dos serviços educacionais é parte da tarefa mais ampla de construção de um Sistema Nacional Articulado” (idem). 
A despeito das importantes questões debatidas nos documentos do PME acerca da indução e que demarcam a necessidade de as políticas sociais conferirem espaço, em sua elaboração, para os anseios e desafios locais, enquanto ação indutora o PME apresentou conflitos que caminham na contramão do que se pretendia. Tais conflitos foram identificados em diversas pesquisas na área da educação, estando presentes também em nossas investigações. Entre esses conflitos, Barbosa (2015) discute que o PME, em seu modelo indutor, promoveu um processo de institucionalização de “ajustes e encurtamentos”, que são improvisos adotados na implementação da política visando contornar a ausência de condições adequadas para a ampliação da jornada escolar, argumentando que, no âmbito do respectivo programa federal, tais processos tornaram-se "não mais aspectos de determinada conjuntura, mas um recurso amplamente utilizado pelas administrações locais como um "modos operandi” de ampliar a oferta, sendo até mesmo incorporado, sistematizado e induzido pelo Governo Federal como um recurso gerencial” (p.90).

Além de institucionalizar ajustes e encurtamentos visando possibilitar, ainda que de forma precária, a ampliação da jornada escolar, o modelo indutor do PME implicou processos que apontam para a precarização do trabalho docente (OLIVEIRA, 2014). Não obstante, Soares (2013) ressalta que, enquanto ação indutora, o respectivo programa promove uma transferência indevida de responsabilidades, pois se ampara na "ajuda da iniciativa privada e entidades não governamentais para através de parcerias suprir as atribuições [que] são próprias [ao Estado]” (p. 145).

Após esta seção panorâmica, em que aspectos significativos da implantação e da implementação do Programa Mais Educação foram evidenciados com o sentido de iluminar as discussões que se seguem, nos perguntamos: Como esse Programa se materializou em municípios brasileiros? Quais 'soluções locais' foram encontradas, visando à uma ampliação da jornada escolar com qualidade?

\section{Programa mais educação em ponte nova e São João Del-Rei: (re)desenhos de duas experiências, a partir de uma indução}

Esta seção se debruça, inicialmente, sobre aspectos da materialização do Programa Mais Educação na Rede Municipal de Ponte Nova, no ano de 2014, em sua relação com a proposta do Programa, não desconsiderando as "interdições, redirecionamentos, conforme os interesses políticos, econômicos, e o universo simbólico-cultural instituídos pelos poderes locais" (SILVA; SILVA, 2014, p. 3) 
Nesse ano, três escolas da rede ofereciam educação em tempo integral para alguns alunos do Ensino Fundamental, somando 256 crianças contempladas pela ampliação da jornada no município - 4,5\% dos alunos de toda a rede e 16,1\% dos alunos do Ensino Fundamental, indo na linha focal preconizada pelo PME. As atividades do Programa aconteciam todos os dias da semana, por mais 4 horas e meia, totalizando jornada diária escolar de 8 horas e meia, carga horária além do mínimo de sete horas que caracteriza a educação em tempo integral no país.

O "Projeto Mais Educação", como denominado na rede, era coordenado pela assessoria direta da secretária de educação e pelo chefe de Ensino Fundamental, revelando a inexistência de um setor específico para gestão e planejamento da educação em tempo integral na Secretaria Municipal de Educação (SEMED); e nas escolas, por professor contratado. A SEMED participava das experiências coordenando-as, avaliando-as, oferecendo espaço físico e recursos humanos em seu desenvolvimento, além de formações para a equipe, sem periodicidade definida. A educação em tempo integral financiava-se pelo PDDE, FUNDEB e por recursos próprios da prefeitura, sendo estes destinados à alimentação; conserto e manutenção de equipamentos; pagamento de pessoal; reformas de espaços escolares e transporte escolar.

Algumas funções públicas para desenvolvimento das atividades específicas do PME em Ponte Nova foram normatizadas pela lei municipal n. 3.739, de 2013 (PONTE NOVA, 2013), fato que nos interessa sobremaneira pois, apesar do município tomar para si os dispêndios referentes às funções elencadas anteriormente, previa sua extinção quando do encerramento do Programa, o que dissociava tal lei da composição de uma política pública de educação em tempo integral própria do município.

Na perspectiva de análise desse importante documento normativo, foram instituídos os cargos de professor comunitário, com carga horária de 40 horas e $25 \mathrm{~h}$ semanais, a depender do número de turnos atrelados ao PME (Art. 1, §1), em consonância com a orientação do MEC, que previa sua criação (BRASIL, 2014b). No preenchimento desse cargo, foi dada preferência aos professores efetivos da unidade escolar (Art. 1, $\$ 3^{\circ}$ do Anexo I), também em consonância com a indicação do MEC (BRASIL, 2009a).

A escolaridade exigida a esses profissionais era a graduação em Pedagogia, habilitação em Supervisão Pedagógica ou licenciatura plena acumulada, no mínimo, com pósgraduação lato sensu em Supervisão Pedagógica; experiência docente de três anos e em coordenação e/ou acompanhamento de projetos educacionais e/ou sociais e conhecimento básico em informática, revelando uma preocupação com a formação e competência profissional de tais professores (PONTE NOVA, 2013). 
A lei municipal ainda normatizou a função de assistente de acompanhamento pedagógico, com carga horária de 25 horas semanais indicando que, na compreensão da rede, esse trabalho não poderia se dar apenas voluntariamente, tal como previsto pelo MEC, além do cargo de auxiliar de serviços gerais, cuja carga horária correspondia a 40 horas semanais. Para o cargo de assistente de acompanhamento pedagógico, no mínimo o Ensino Médio na modalidade Normal era requisito, enquanto para o de auxiliar de serviços gerais, o Ensino Fundamental era a base. Essa normatização municipal ainda indicava a forma de contratação para tais cargos, que se daria por contrato administrativo por tempo determinado, por meio de processo seletivo simplificado, considerando critérios de maior escolaridade, maior tempo de serviço na área de educação pública e/ou privada e maior idade.

Entretanto, a lei n. 3.739, de 2013 (PONTE NOVA, 2013) não normatizou a contratação de profissionais para atuação em todos os macrocampos do Programa Mais Educação, firmando-se no de Acompanhamento Pedagógico: Prescindiriam as áreas contempladas por tais macrocampos, de profissionais com formação e experiência pedagógica? Não seriam as áreas contempladas pelo macrocampo de Acompanhamento Pedagógico, passíveis de interlocução com outros sujeitos?

No que diz respeito à materialização do PME na escola pesquisada, segundo sua diretora, inicialmente a dimensão do improviso imperava, o que foi atenuado com a construção de duas salas de aula para os alunos que permaneciam em tempo integral. Outros espaços da escola eram utilizados - como pátio, quadra (quando não utilizada pelo ensino regular), biblioteca e sala de informática, mas gramado, corredores e áreas abertas, em geral eram consideradas inapropriadas, diante da 'indisciplina' dos alunos. Foi observada a ressignificação, pelos estudantes, de espaços debaixo de mesas e cadeiras, vistos como "não lugares" para se brincar pela equipe atuante nas atividades, o que demonstrava uma compreensão destoante da proposta do PME, que pretendia romper com a lógica marcada por espaços delimitados rigidamente (BRASIL, 2011). Fora da escola também não era lugar de aprender, devido ao "alto nível de perigo" do bairro.

As observações realizadas nos indicaram que tanto a falta de estrutura da escola, quanto a de equipamentos educativos no bairro e de condições de segurança para o trânsito dos alunos eram obstáculos à ampliação dos espaços educativos, ou seja, esse território não apresentava condições 'educadoras', premissa estruturante da concepção de educação integral em tempo integral do PME. A concepção de espaço educativo de sujeitos envolvidos na materialização do Programa foi outro entrave observado, nesse caso, restringindo-se as atividades aos espaços educativos na própria escola. 
No que tange aos macrocampos desenvolvidos no ano de 2014, para além do Acompanhamento Pedagógico, a escola observada desenvolveu os de Esporte, Lazer e Cultura e Artes e Educação Patrimonial, cujas escolhas se basearam nos espaços, bem como nos voluntários disponíveis e, em segundo plano, no interesse dos alunos.

Outras práticas observadas no âmbito do PME nessa escola foram (1) a suspensão de alunos das atividades do projeto por motivos como briga com os colegas, agressão verbal, realização de atividades de forma "errada", além do trânsito em espaços da escola e (2) o "castigo", com proibição de frequência às oficinas de Esporte e Lazer, Teatro, Percussão e Desenho; “mais” cópia de textos; “mais” leitura; “mais” Matemática ou 'dever de casa’; extinção do lanche ou almoço, por motivos como não realização de atividade de Acompanhamento Pedagógico. Tais práticas, entre outras, além de revelarem uma incompreensão dos propósitos do Programa, promoveram exclusão e revelaram uma faceta perversa da indução.

Sintetizando o que apresentamos até o momento, entendemos que, no âmbito da implantação do PME no município de Ponte Nova, a indução se consolidou a partir de normatização específica, no que tange a alguns cargos, e, também, de práticas diferenciadas daquelas propostas pelo Programa indutor, possibilitando 'soluções locais' em sua continuidade. No tocante à escola pesquisada, o PME induziu uma educação em tempo integral à revelia da educação integral preconizada em sua proposta - se considerarmos a concepção contemporânea de uma educação integral intersetorial, intercultural, a partir das potencialidades educativas do bairro e dos agentes culturais. Isso aconteceu porque a escola situava-se em bairro que apresentava limitações, no que dizia respeito aos equipamentos culturais e à segurança. Neste caso, a "solidariedade" da sociedade não se revelou efetiva, no que tange a possibilidades de parcerias que alavancassem o Programa. No mesmo sentido, não observamos a convergência de diversos setores da gestão pública, rumo a uma educação integral intersetorial na rede municipal em questão.

Entendemos que a indução de uma educação integral que considere a contribuição de vários sujeitos da comunidade na formação intercultural dos alunos não prescinde da responsabilidade de profissionais pedagogicamente preparados para o planejamento e inserção de saberes provenientes desses sujeitos nas atividades escolares, sob o risco de perpetuarem concepções tradicionais e dos estudantes passarem por mais processos excludentes na escola, a despeito daqueles que já passam.

Apesar disso, entendemos também que o PME, nessa escola, pareceu cumprir o papel de controle social que inferimos compor o papel da educação integral em tempo integral diante das necessidades de ajuste do capitalismo, a fim de lidar com as mazelas sociais, garantindo a estabilidade do sistema. 
No que diz respeito ao nosso segundo município pesquisado - São João del-Rei (SJDR) - podemos dizer que sua trajetória de educação em tempo integral inicia-se em 2013, com a adesão da Secretaria Municipal de Educação ao Programa Mais Educação. Ao longo dos últimos seis anos, a rede municipal passou por um processo de articulação entre programas federais e programas municipais que foram responsáveis pela ampliação da jornada escolar em 11 das 18 instituições de Ensino Fundamental, com o objetivo de garantir a jornada de tempo integral a, pelo menos, $25 \%$ dos estudantes.

Fazendo uma síntese dessa trajetória, podemos dividi-la em dois momentos: o primeiro, representado pela adesão ao PME, no final de 2013 e pela sua interrupção no ano de 2015, o que levou a rede a articular o seu primeiro programa municipal, em 2016, intitulado Programa de Educação Integral Municipal. Já o segundo momento é representado pela interrupção do programa municipal e pela implementação do Programa Novo Mais Educação (PNME), no ano de 2017. Em 2018, o PNME foi implementado juntamente com um segundo programa municipal, intitulado Programa Municipal Escolas em Tempo Integral. Neste ensaio, ocupamo-nos, especificamente, do primeiro momento aqui enunciado.

De acordo com os elementos basilares do Programa Mais Educação já expostos anteriormente, podemos encontrar aproximações e distanciamentos com a implementação do Programa de Educação Integral Municipal/SJDR. Considerando que o processo indutor federal se materializou com um relativo sucesso no município, identificamos que a implementação da política se orientou pelas bases do programa federal. Contudo, há diferenças notórias entre a proposta documental do PME e a implementação do Programa de Educação Integral Municipal que, de acordo com nossa pesquisa, se referem a dois principais aspectos, os quais representam o mesmo processo: (i) a idealização do PME em âmbito federal se deu de forma extremamente distante das condições materiais para implementação do programa; (ii) em nível municipal, as condições objetivas para implementação da política de Educação em Tempo Integral também não foram capazes de seguir todas as diretrizes preconizadas pelo programa federal.

Nesse sentido, notamos que as diferenças entre a proposta federal e a referida política municipal se deram em virtude, mais de dificuldades vinculadas, predominantemente, à ausência de recursos financeiros, do que por divergências ideológicas ou de concepções educacionais.

Ao encontro do que discutimos sobre o PME, Silva (2015, p. 205) indica a "intersetorialidade, a diversificação das atividades - por meio de oficinas realizadas no contraturno, e a participação comunitária”, como os elementos centrais desse programa. Dessa maneira, percebemos que a política municipal se distanciou significativamente do 
programa federal no que tange ao primeiro e último aspecto referido; porém, se aproximou consideravelmente do mesmo, no que se refere à diversificação das atividades.

A intersetorialidade no Programa de Educação Integral Municipal se limitou a parcerias pontuais com a Secretaria Municipal de Esporte e com o Batalhão da Polícia Militar, que auxiliaram na promoção de atividades de Esporte e Lazer. A participação comunitária também não foi desenvolvida de maneira significativa, restringindo-se à promoção de algumas ações esparsas no âmbito das oficinas pedagógicas, mas sem constituir uma regularidade e sem se incorporar ao Projeto Político Pedagógico das instituições escolares. A concepção da cidade enquanto um espaço com diversos "territórios educativos" - aspecto caro ao PME, e que também se relaciona com a participação comunitária -, não teve forte apelo no desenvolvimento das ações do programa. Assim, entre seus elementos basilares, o único que demarcou fortemente o processo de implementação da política municipal foi a diversificação das atividades, ainda que de uma maneira mais enxuta que no Programa Federal.

O programa municipal organizou-se em quatro eixos curriculares: acompanhamento pedagógico, (ii) educação empreendedora; (iii) cultura, artes e educação patrimonial e (iv) esporte e lazer. Nessa perspectiva, a política municipal não estabeleceu “comunicação e cultura digital', 'educação ambiental”, educação em "Direitos Humanos” e "promoção da saúde" como saberes que compuseram um macrocampo específico, conforme estabelecia o PME. Cabe destacar que, ao oferecer esses componentes, o Programa de Educação Integral Municipal expressou, no campo documental, concepções educacionais similares às do PME, algo que pode ser identificado em sua apresentação, ao afirmar que o programa municipal fora articulado, considerando "a importância da escola como espaço social no qual a vivência democrática pode ser exercitada por meio de atividades lúdicas e recreativas” (SÃO JOÃO DEL-REI, 2016).

Além dos aspectos que compõem a base do PME, indicamos em nossas análises outros aspectos relevantes que aproximaram e distanciaram a política municipal das diretrizes do programa federal. Este ressaltava, em suas diretrizes, a importância de superar uma lógica bipartida na educação em tempo integral, dividida em turno e contraturno (BRASIL, 2009d, p. 32) que, em geral, expressa dicotomia - o turno se constitui pelas disciplinas consideradas acadêmicas e de maior relevância formativa e o contraturno se traduz na oferta de oficinas "complementares", destinadas aos "aspectos lúdicos”. Contudo, a superação da lógica bipartida exige condições estruturais, materiais e de recursos humanos para implementação de um projeto pedagógico que promova uma organicidade em tais atividades, vinculando-as a uma ideia de formação integral. Tais condições não se fizeram presentes no município, o que resultou em uma reprodução das referidas dicotomias. 
Embora tais aspectos sejam limitadores de uma concepção de educação em tempo integral alinhada a uma educação integral sócio historicamente referenciada na emancipação, o Programa de Educação Integral Municipal foi constituído de forma a tentar superar ao menos um dos sentidos compensatórios do PME. A política federal se delineava pela focalização do programa nas instituições com baixo Índice de Desenvolvimento da Educação Básica (IDEB) e aos indivíduos em vulnerabilidade socioeconômica. Em âmbito municipal, conforme expressa a fala da Coordenadora Pedagógica ocorreu uma tentativa de ampliar o alcance da educação em tempo integral:

Nós montamos o perfil dos alunos (...), que são as crianças em risco, vulnerabilidade. Nós incluímos estes estudantes, mas deixamos bem livre o processo de seleção para quem quisesse e tivesse interesse, a proposta do programa foi explicada aos pais (COORDENADORA PEDAGÓGICA - SME).

Cabe destacar um último aspecto que aproxima os dois programas: a promoção de oficinas, por meio do voluntariado, que foi reproduzida no Programa de Educação Integral Municipal, conforme estabeleciam as diretrizes do PME. No entanto, tal direcionamento acarretou diversos conflitos que tornaram inviáveis a promoção das oficinas pedagógicas somente com sujeitos voluntários. Assim, o município passou a implementar sua política por meio de diferentes formas de contratação, situação que, em geral, garantiu contratos temporários, regidos pela CLT, aos profissionais que atuavam no âmbito das oficinas de Língua Portuguesa e Matemática, enquanto promoveu formas de trabalho mais precarizadas aos profissionais dos demais campos, o que incluiu mecanismos de terceirização do trabalho docente, voluntariado com ressarcimento de custos e voluntariado sem nenhuma contrapartida por parte do poder executivo.

Sintetizando essas reflexões como fizemos com aquelas apresentadas sobre a experiência do município de Ponte Nova, podemos dizer que o processo indutor em São João del-Rei se deu por meio de avanços normativos na legislação municipal e que redundaram em soluções locais, entre elas a elaboração de uma política própria de educação em tempo integral realizada exclusivamente com recursos municipais. Embora em âmbito municipal tenha ocorrido uma tentativa de implementação do Programa de Educação Integral conforme as diretrizes do PME, algumas alterações foram necessárias para que a política municipal pudesse ser implementada.

Nesse sentido, a dificuldade na promoção de parcerias intersetoriais estáveis e com agentes da sociedade civil fez com que a política tenha sido implementada de forma centralizada, tendo como referência única a Secretaria Municipal de Educação e, no campo das ações pedagógicas, se limitou ao espaço das instituições escolares. No campo curricular houve uma 
aproximação às bases do PME, contudo promovendo uma articulação mais enxuta dos macrocampos, possivelmente visando a racionalização dos recursos. Por fim, em relação aos profissionais em atuação, houve necessidade de estabelecer contratos em formatos que não se limitassem ao voluntariado, de forma a garantir a regularidade das oficinas pedagógicas efetivando, nesses moldes, a implementação do Programa de Educação Integral Municipal.

\section{CONSIDERAÇÕES}

Em nossas Considerações, compreendemos o slogan da educação integral em tempo integral no PME permeado pelas funções social e econômica da educação, tal como previsto pelas orientações de organismos internacionais para os países periféricos na virada do milênio. Trata-se de um slogan potencial para a promoção do consenso, tendo em vista a demanda histórica das classes trabalhadoras por uma educação ampliada (NEVES, et al, 2015).

Partindo das orientações desses organismos, entendemos que não é construída uma concepção mais precisa, a partir do que se compreende compor a integralidade formativa dos sujeitos; mas, tendo em vista elementos que vão ao encontro dessas orientações, forja-se uma educação integral em tempo integral circunscrita a bens socioemocionais já disponíveis na sociedade. Trata-se de um processo que, ao 'romantizar' o espírito de solidariedade e de colaboração presente na sociedade civil - rumo ao provimento de dimensões formativas para os alunos e alunas das escolas públicas -, mascara a natureza de classe dessa sociedade não harmônica, conflitiva e que apresenta diferentes interesses em relação a projeto de educação para a classe trabalhadora.

Reconhecemos o potencial educativo da comunidade local e sua necessidade de diálogo com a educação escolar; porém entendemos que, nos moldes como se configura no PME, esse entrelaçamento aparenta mais uma justificativa para a desresponsabilização do Estado por uma educação que vá ao encontro das demandas das classes populares, do que fundamento de uma educação escolar que integra conceitos científicos e conceitos cotidianos, trazendo-os ao patamar do conhecimento cognitivo, conforme aponta Libâneo (2014).

Induz-se, assim, uma concepção de educação integral em tempo integral eficiente para a promoção da coesão social e para o apassivamento das massas, visando o controle social num período que, conforme Motta (2012), impera o medo da rebelião dos trabalhadores frente à situação de desemprego, miséria e fome, fruto da primeira etapa do neoliberalismo. 
A materialidade das experiências revela que a indução se dá de forma difusa, por vezes próxima, por vezes distanciada da concepção proposta nos documentos do Programa Mais Educação, promovendo mais exclusão, haja vista a precariedade das condições estruturais e a desromantização da capacidade educadora do território, no que tange à educação escolar. Entendemos, assim, que “o trabalho pedagógico não pode eximir-se de uma determinação de sentido da práxis educativa, já que intervém no destino humano, na formação e no ser humano dos educandos” (LIBÂNEO, 2010, p. 192).

Os aspectos apresentados se inserem na formatação do que compõe a noção do Programa Mais Educação como indutor da educação em tempo integral, visto que a ideia de indução dessa educação é constituída por meio da inter-relação de três diferentes campos: econômico, político e pedagógico. Nesse sentido, ainda que o escopo documental enuncie a indução de uma educação integral em tempo integral, a materialidade evidencia barreiras significativas para uma proposta com pressupostos emancipadores, tendo em vista que o campo econômico e político, nas suas relações com o campo pedagógico tem, nos resultados de suas correlações de força, forjado direcionamentos que implicam uma concepção instrumental e economicista de educação.

Sabemos que tal caminho não se articula em mão única, ou seja, existem tensionamentos e embates em tais relações. Dessa forma, o rompimento com tais concepções educacionais constitui elemento fundamental para a possibilidade de construção de um projeto em que o tempo integral se teça a partir de uma concepção de educação integral fundada em preceitos emancipatórios.

Frisamos o termo preceitos, pois só há possibilidade de real emancipação mediante superação do modelo capitalista. Contudo, isso não significa que a Educação esteja limitada à reprodução de um projeto de formação balizado pelo status-quo, pois o rompimento com a hegemonia de uma concepção econômica de educação pode contribuir para uma formação crítica que, somada a outros elementos da vida social, fomentam possibilidades de enfrentamento de regimes autoritários e avessos a qualquer valorização da dimensão social do espaço público.

\section{Referências}

BARBOSA, J. M. A educação integral dos territórios educativos do programa mais educação em Caruaru-PE: a institucionalização de ajustes e encurtamentos no interior das escolas. 2015. 284f. Dissertação (Mestrado em Educação), Universidade Federal de Pernambuco UFPE, Caruaru-PE. Disponível em: https://repositorio.ufpe.br/handle/123456789/17231. Acesso em: 20/08/2018. https://doi.org/10.21474/ijaro1/8390 
BRASIL, Ministério da Educação: Manual operacional de educação integral 2014. Diário Oficial da União. Brasília, DF, 2014b. Disponível em:

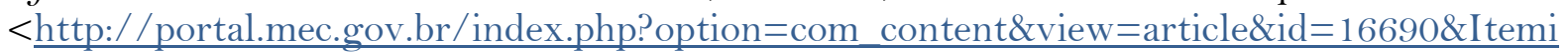
$\mathrm{d}=1113>$. Acesso em: 01 mai. 2019.

BRASIL. Decreto n. 6.253 de 13 de novembro de 2007. Dispõe sobre o Fundo de Manutenção e Desenvolvimento da Educação Básica e de Valorização dos Profissionais da Educação - FUNDEB, regulamenta a Lei n. 11.494 de 20 de junho de 2007 e dá outras providências. Diário Oficial da União, Brasília, DF, 14 de novembro 2007a. Disponível em: $<$ http://www.planalto.gov.br/ccivil_03/_ato2007-2010/2007/Decreto/D6253.htm>.

Acesso em: 02 mai. 2019. https://doi.org/10.26512/2015.12.d.20933

BRASIL. Decreto n. 7.083 de 27 de janeiro de 2010. Dispõe sobre o Programa Mais Educação. Diário Oficial da União, Brasília, DF, 27 de janeiro de 2010. Disponível em: $<$ http://www.planalto.gov.br/ccivil 03/ ato2007-2010/2010/decreto/d7083.htm>. Acesso em: 20 abr. 2019. https://doi.org/10.21680/1981-1802.2013v45n31id5111

BRASIL. Lei n. 13.005 de 25 de junho de 2014. Aprova o Plano Nacional de Educação e dá outras providências. Diário oficial da União, Brasília, DF, 25 jun. 2014a. Disponível em: $<$ http://www.planalto.gov.br/ccivil 03/ Ato2011-2014/2014/Lei/L13005.htm>. Acesso em 30 mar. 2019. https://doi.org/10.19177/prppge.v8e132014276-286

BRASIL. Ministério da Educação. Mais Educação: cartilha caminhos para elaborar uma proposta de educação integral em jornada ampliada. Brasília: SEB/MEC, 2011. Disponível em: < http:// portal.mec.gov.br/index.php?option=com_docman\&view=download\&alias=8194-4caminhos-elaborar-educacao-integral-cecipe-seb-pdf\&category_slug=junho-2011-

pdf\&Itemid=30192 >. Acesso em: 07 mai. 2019. https://doi.org/10.11606/d.48.2014.tde$\underline{17122014-103428}$

BRASIL. Ministério da Educação. Programa Mais Educação - Manual passo a passo. Brasília, D.F: MEC, 2009a. Disponível em: $<$ http://portal.mec.gov.br/dmdocuments/passoapasso_maiseducacao.pdf>. Acesso em: 07 mai. 2019.

BRASIL. Ministério da Educação. Série Mais Educação - Rede de Saberes Mais Educação. Pressupostos para Projetos Pedagógicos de Educação Integral. Brasília: MEC, 2009c. Disponível $\mathrm{em}: \quad<$ http://portal.mec.gov.br/dmdocuments/cad_mais_educacao_2.pdf>. Acesso em: 07 mai. 2019. https://doi.org/10.11606/d.48.2014.tde-17122014-103428

BRASIL. Ministério da Educação. Série Mais Educação - Educação Integral: texto referência para o debate nacional. Brasília: Ministério da Educação, Secretaria de Educação Continuada, Alfabetização e Diversidade. 2009d. Disponível em: http://portal.mec.gov.br/dmdocuments/cadfinal_educ_integral.pdf. Acesso em: 02 mai. 2019. https://doi.org/10.1590/0104-93132016v22n1p270

BRASIL. Ministério da Educação. Série Mais Educação - Gestão intersetorial no território. Brasília: Ministério da Educação, Secretaria de Educação Continuada, Alfabetização e Diversidade, 2009b. Disponível em: $<$ http://portal.mec.gov.br/dmdocuments/cader_maiseducacao.pdf $>$. Acesso em: 07 mai. 2019. https://doi.org/10.1590/0104-93132016v22n1p270 
BRASIL. Portaria Normativa Interministerial n. 17, de 24 de abril de 2007. Institui o Programa Mais Educação que visa fomentar a educação integral de crianças, adolescentes e jovens, por meio do apoio a atividades socioeducativas no contraturno escolar. Diário Oficial da União, Brasília, DF, 26 de abril de 2007b. Disponível em: <www.portal.mec.gov.br>. Acesso em: 20 abr. 2019. https://doi.org/10.19177/prppge.v4e82011422-439

BRASIL. Resolução n. 2, de 14 de abril de 2016. Destina recursos financeiros, nos moldes operacionais e regulamentares do Programa Dinheiro Direto na Escola (PDDE), a escolas públicas municipais, estaduais e do Distrito Federal, a fim de contribuir para que estas realizem atividades de educação em tempo integral, em conformidade com o Programa Mais Educação. Diário Oficial da União, Brasília, DF, 14 de abril de 2016. Disponível em: $<$ https://www.fnde.gov.br/fndelegis/action/UrlPublicasAction.php?acao=abrirAtoPublico $\& s g l \_$tipo $=$RES\&num_ato $=00000002 \&$ seq_ato $=000 \& v 1 r \_$ano $=2016 \& s g l \_$orgao $=$CD $/ \mathrm{FND}$ E/MEC>. Acesso em: 07 mai. 2019. https://doi.org/10.26512/2006.03.tcc.475

CAVAliere, A. M. V; COELHO, L. M. C. C. Para onde caminham os CIEPs? Uma análise após 15 anos. São Paulo, Cadernos de Pesquisa. n.119, julho/2003. P.147-176. https://doi.org/10.1590/s0100-15742003000200008

COELHO, L. M. C. C; SIRINO, M. B. Concepções de educação integral, gestã do tempo integral e projeto(s) de sociedade: um debate (mais do que) atual. In: FERREIRA, Antonio Gomes; BERNADO, Elisangela da Silva e MENEZES, Janaina Specht da Silva. Politicas e gestão em educação em tempo integral - Desafios contemporâneos. Curitiba, CRV, 2018. https://doi.org/10.1590/s1413-24782017227170

LIBÂNEO, J. C. Escola de tempo integral em questão: lugar de acolhimento social ou ensino-aprendizagem? In: VALDENIZA, M. L. B. (org.). Educação: ensino, espaço e tempo na escola de tempo integral. Goiânia: Gráfica UFG, 2014. p. 257-308. https://doi.org/10.15599/0104-4834/cogeime.v26n51p93-101

LiBÂNEO, J. C. Pedagogia e pedagogos, para que? 11. ed. São Paulo: Cortez Editora, 2010. v. 1. $208 \mathrm{p}$.

LIBÂNEO, J. C. Políticas educacionais no Brasil: desfiguramento da escola e do conhecimento escolar. Cadernos de Pesquisa (Fundacao Carlos Chagas), v. 46, p. 38-62, 2016. Disponível em: < http://www.scielo.br/pdf/cp/v46n159/1980-5314-cp-46-159-00038.pdf>. Acesso em: 07 mai. 2019. https://doi.org/10.1590/198053143572

MOTTA, V. C. Ideologia do capital social: atribuindo uma face mais humana ao capital. 1. ed. Rio de Janeiro: EDUERJ, 2012. v. 1. 310p.

NEVES, L. M. W.; MARTINS, A. S.; MELO, A. A. S. de; BRAGA, I. F. ; SOUZA, C. A. . Mudanças na educação básica no capitalismo neoliberal de Terceira Via no Brasil. In: Lúcia Maria Wanderley neves; André Silva Martins. (Org.). Educação básica: tragédia anunciada? O1 ed.São Paulo: Xamã, 2015, v. 01, p. 23-44. https://doi.org/10.1590/1981-7746-sip00122

OLIVEIRA, L. G. A formação continuada no âmbito do programa mais educação no município de Mesquita-RJ. 2014. 152f. Dissertação (Mestrado em Educação), Universidade Federal do Estado do Rio de Janeiro - Unirio, Rio de Janeiro-RJ. Disponível em: https://docs.google.com/file/d/oB-sE2Ar37CoNR2RoNnZoSkhlaG8/edit. Acesso em: 20/08/2018. https://doi.org/10.14507/epaa.v22n59.2014 
PONTE NOVA. Lei n 3.739 de 25 de março de 2013. Dispõe sobre a criação de funções públicas para o desenvolvimento das atividades específicas do Programa Federal Mais Educação e dá outras providências. Diário Oficial do Município, Ponte Nova, MG, 25 de março de 2013. Disponível em: <http://www.camarapontenova.mg.gov.br/ler_legislacao.asp?id=3331>. Acesso em: 29 mar. 2015. https://doi.org/10.1590/0034-716719730005000016

SÃO JOÃO DEL-REI - MG. Decreto $n^{\circ}$. 6.456, de 14 de março de 2016. Dispõe sobre a criação da Educação Integral na Rede Municipal de Educação de São João del-Rei, e dá outras providências. São João del-Rei - MG, mar. 2016. https:// doi.org/10.17138/tgft(2)82-84

SILVA, B. A. R. Diferenças entre as perspectivas de educação integral em Anísio Teixeira e no programa Mais Educação. Revista HISTEDBR On-line, Campinas, n. 61, p. 202-218, mar. 2015.

Disponível

em:

https://periodicos.sbu.unicamp.br/ojs/index.php/histedbr/article/view/8640523. Acesso em: 22/08/2018. https://doi.org/10.20396/rho.v15i61.8640523

SILVA, J. A.;_SILVA, K. N. P. Analisando a concepção de Educação Integral do governo Lula/Dilma através do Programa Mais Educação. Educação em Revista, Belo Horizonte, v. 30, p. 95-126, 2014. Disponível em: <http://www.scielo.br/scielo.php?pid=So 10246982014000100005\&script=sci_arttext>. Acesso em: 30 mar. 2019. https://doi.org/10.1590/s0102-46982014000100005

SOARES, D. P. A. Programa mais educação nas escolas estaduais de Porto Velho-RO: percursos para a educação integral. 2013. 182f. Dissertação (Mestrado em Educação), Universidade Federal de Rondônia - UNIR, Porto Velho-RO. Disponível em: http://www.ppge.unir.br/uploads/62248421/arquivos/DISSERTA_O__DOMINGOS_P ERPETUO_ALVES_SOARES_944182428.pdf. Acesso em: 20/08/2018. https://doi.org/10.14393/19834071.2012.17137

TEIXEIRA, Anísio. Educação não é privilégio. São Paulo: Cia. Editora Nacional, 1957. 